\title{
Emotional intelligence: influencing factors and impact on nurses in intensive care
}

\author{
Inteligência emocional: fatores influenciadores e impacto nos enfermeiros em cuidados \\ intensivos
}

Rúben Miguel Câmara Encarnação ${ }^{1}$, Eduardo Manuel da Cunha Soares², António Luís Rodrigues Faria de Carvalho ${ }^{3}$

Objective: to analyze the evidence on the factors that influence the emotional intelligence of intensive care nurses. Methods: systematic review of the literature. We used the databases CINAHL Complete, Academic Search Complete, MedicLatina, Psychology and Behavioral Sciences Collection, MedLine with Full Text (via EBSCO HOST), MedLine Complete (via PubMed), SCOPUS and other sources, such as Google Scholar, clinical trial registration sites and manual/cross-references search. A total of 1,307 articles were published until April 2018, and nine were included in the study. Results: the factors that influenced nurses' emotional intelligence were age, sex, emotional experience, training and personality; and the impact of emotional intelligence was translated on a personal, professional and caring level. Conclusion: the practice of nursing in intensive care units is influenced by the nurse's emotional intelligence. This intelligence is affected by several factors and, because it is learned, must be stimulated in formative contexts.

Descriptors: Emotional Intelligence; Critical Care; Nursing.

Objetivo: analisar as evidências sobre os fatores que influenciam a inteligência emocional dos enfermeiros de cuidados intensivos. Métodos: revisão sistemática da literatura. Recorreu-se às bases de dados CINAHL Complete, Academic Search Complete, MedicLatina, Psychology and Behavioral Sciences Collection, MedLine with Full Text (via EBSCO HOST), MedLine Complete (via PubMed), SCOPUS e outras fontes como Google Scholar, sites de registro de ensaios clínicos e busca manual-referências cruzadas. Foram encontrados 1.307 artigos publicados até abril de 2018, sendo incluídos nove. Resultados: os fatores que influenciaram a inteligência emocional dos enfermeiros foram a idade, sexo, experiência emocional, formação e personalidade; e o impacto da inteligência emocional traduziu-se a nível pessoal, profissional e no cuidar. Conclusão: a prática de enfermagem em unidades de cuidados intensivos é influenciada pela inteligência emocional do enfermeiro. Esta inteligência é afetada por diversos fatores e, por ser apreendida, deve ser estimulada em contextos formativos.

Descritores: Inteligência Emocional; Cuidados Críticos; Enfermagem.

\footnotetext{
${ }^{1}$ Centro Hospitalar São João, Escola Superior de Enfermagem do Porto. Portugal.

${ }^{2}$ Instituto Português de Oncologia do Porto. Porto, Portugal.

${ }^{3}$ Escola Superior de Enfermagem do Porto. Porto, Portugal.

Corresponding author: Rúben Miguel Câmara Encarnação

Rua Dr. António Bernardino de Almeida, 830 - Escola Superior de Enfermagem do Porto, CEP: 4200-072. Porto, Portugal. E-mail: ruben. enfe@gmail.com
} 


\section{Introduction}

Intensive care units, because of their uniqueness, are environments that require permanent medical and nursing care, and that frequently bring the need responding to situations of sudden changes in patients' clinical conditions ${ }^{(1)}$. This requires health professionals to have specific skills and knowledge to make high-complexity decisions in a timely manner ${ }^{(1)}$. On the other hand, these units are characterized by sophisticated equipment, demanding routines and a great confrontation of professionals with patients' pain and imminence of the death ${ }^{(2)}$. Due to the intensity of care required, professionals, especially nurses, experience physical and emotional exhaustion, and it is essential that they are able to recognize and manage their own emotions so that they can provide quality care $^{(1)}$.

The concept of emotional intelligence is understood as the set of capacities of the individual to identify their own emotions, manage and understand other emotional phenomena and motivate themselves in situations that are embarrassing, problematic and generate intrinsic and extrinsic conflicts ${ }^{(3-4)}$. Emotional intelligence reflects in the professional's attitudes and behaviors in different contexts and, therefore, has an impact on the quality of their performance ${ }^{(3)}$.

Thus, emotional intelligence is important for professional performance, since professionals that are socially integrated, emotionally stable and motivated are more capable; however, only recently interest has been shown in the provision of training on emotional intelligence, as a means to promote the management of conflicts and stress and the well-being of nursing professionals $^{(3-4)}$.

Understanding and valuing the emotional intelligence of nurses in intensive care as a conditioning factor of their behaviors, reflects an attitude of responsibility in the understanding of professional performance, which in turn, will ensure quality care by more effective professionals who give particularly differentiated answers to critically ill patients. In considering nurses' emotional intelligence as an essential tool for critical care practice, we intended to analyze the evidence on the factors that influence the emotional intelligence of intensive care nurses, answering the following research question: What factors influence emotional intelligence in the practice of intensive care nurses?

\section{Methods}

This review is based on the mixed method of systematic literature review of the Joanna Briggs Institute, due to the different methodologies of the included studies ${ }^{(5)}$. A review protocol was created that, by allowing its reproducibility by other researchers, makes the validity and rigor of this study possible. This protocol is characterized by a set of phases that must be followed and that encompass the pertinence of the review, its objectives, the inclusion and exclusion criteria adopted, the method of selection of scientific evidence, evaluation of the methodological quality of the selected articles and the synthesis and analysis of the results obtained ${ }^{(6)}$. This protocol was registered in the Prospero database with registration number CRD42018099512.

For the formulation of the guiding question, the PICO strategy was used, which derives from the acronym: Population, Intervention, Comparison (if applicable) and Outcomes. Thus, the following question emerged as the basis for the present investigation: "What factors influence emotional intelligence (I) in the practice $(\mathrm{O})$ of intensive care nurses (P)?" After the initial question was asked, it was necessary to verify the existence of other revisions on the subject, and no record was found.

In order to select the scientific evidence, it is necessary to define the search terms, for which we have isolated the concepts included in the starting 
question in order to obtain the Boolean phrase. We used the controlled descriptors of the Medical Subject Headings (MeSH Browser ${ }^{\circledR}$ ), the descriptors in health sciences (DeCS $®$ ) and the uncontrolled descriptors/ free terms, reaching the following set of words that constituted the Boolean phrase: emotional intelligenc OR emotional competenc OR emotional understand OR emotional skill OR emotional abilit OR social intelligenc AND critical care OR intensive care OR intensive care unit OR Intensive therapy unit OR icu OR itu OR ccu AND nurs OR nursing staff, hospital.

The survey was conducted during the last week of April 2018, in the following databases: CINAHL ${ }^{\circledR-}$ Complete, Academic Search ${ }^{\circledR}$ Complete, MedicLatina ${ }^{\circledR}$, Psychology and Behavioral Sciences Collection ${ }^{\circledR}$, MedLine $^{\circledR}$ with Full Text (via EBSCO HOST ${ }^{\circledR}$ ), MedLine ${ }^{\circledR}$ Complete (via PubMed ${ }^{\circledR}$ ) and SCOPUS ${ }^{\circledR}$. Further studies were done in other sources, such as Google Scholar, clinical trial registration sites and manual/cross-references search.

Subsequently, the criteria for inclusion and exclusion of the studies were defined, taking into account the type of study, type of participants and type of intervention. Thus, we included primary studies published up to April 2018 and available in full text, which referred to nurses working in intensive care, approached emotional intelligence and were published in the English, Portuguese and Spanish languages, because these are the languages mastered by the reviewers. Qualitative studies were included because of their potential to describe phenomena that have not yet been studied by quantitative methods. Secondary or opinion/commentary studies were not included, nor studies in which the participants were exclusively nursing students, professionals from other areas or nursing heads. Thus, we decided to include all the empirical studies, accepting the studies of level IV to I of scientific evidence ${ }^{(7)}$.

The selection of the studies was carried out by two reviewers, independently, in two phases, when the relevance tests were used. The Relevance Test I, said as preliminary, was used to refine the initial selection of the articles (reading the titles and abstracts). The studies selected in the Relevance Test I underwent a second evaluation - Relevance Test II (full reading of the studies). The search strategy in the databases found 1307 studies (58 EBSCO HOST $®$, 942 via SCOPUS $\AA$ and 307 via PubMed $\AA$ ), of which 52 were duplicated, thus resulting in a total of 1255 articles. No additional studies were found in the other sources.

In line with the Relevance Test I, a first selection was made, with a total of 11 articles. After this selection, we proceeded to the full reading of the studies - Relevance Test II-, after which nine articles were selected.

The evaluation of the methodological quality of the studies included in the systematic review is an essential step in any review protocol, since it is this one that guarantees the reliability of the results and, consequently, the credibility of the review. After reading all the articles in full, it was decided that nine articles would proceed for evaluation of methodological quality by two independent reviewers, using the Joanna Briggs Institute (JBI) Meta Analysis of Statistics Assessment and Review Instrument (JBI-MAStARI), for quantitative studies, and the Qualitative Assessment and Review Instrument (JBI-QARI), for qualitative stu$\operatorname{dies}^{(5)}$. In case of disagreement between the reviewers, a third reviewer was consulted.

Figure 1 illustrates the whole process of research and selection of systematic review articles.

The extraction of the data, being the bridge between the report of the authors of the primary studies and the final report of the reviewers, should follow a well-defined and systematized process ${ }^{(6)}$. Data were extracted by two independent reviewers, and were later discussed until a consensus was reached. A data extraction form was used based on the guidelines of the Joanna Briggs Institute ${ }^{\circledR}$, considering: title, authors, year and place of study, methodological framework, data collection method, objectives, participants, ethical aspects, data analysis, intervention performed, results, conclusion, level of evidence, reviewers' comments and background notes of the study. 


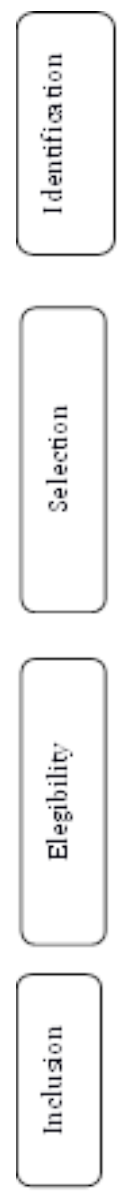

Identified in da tabases: 1.307

- Ebsco Host (58)

- Medline/Pubmed (307)

- Soopus (942)
Identified from other sources (Google S doolar, consultation in dinical trial registation sites and manual/cross reference search): Zero
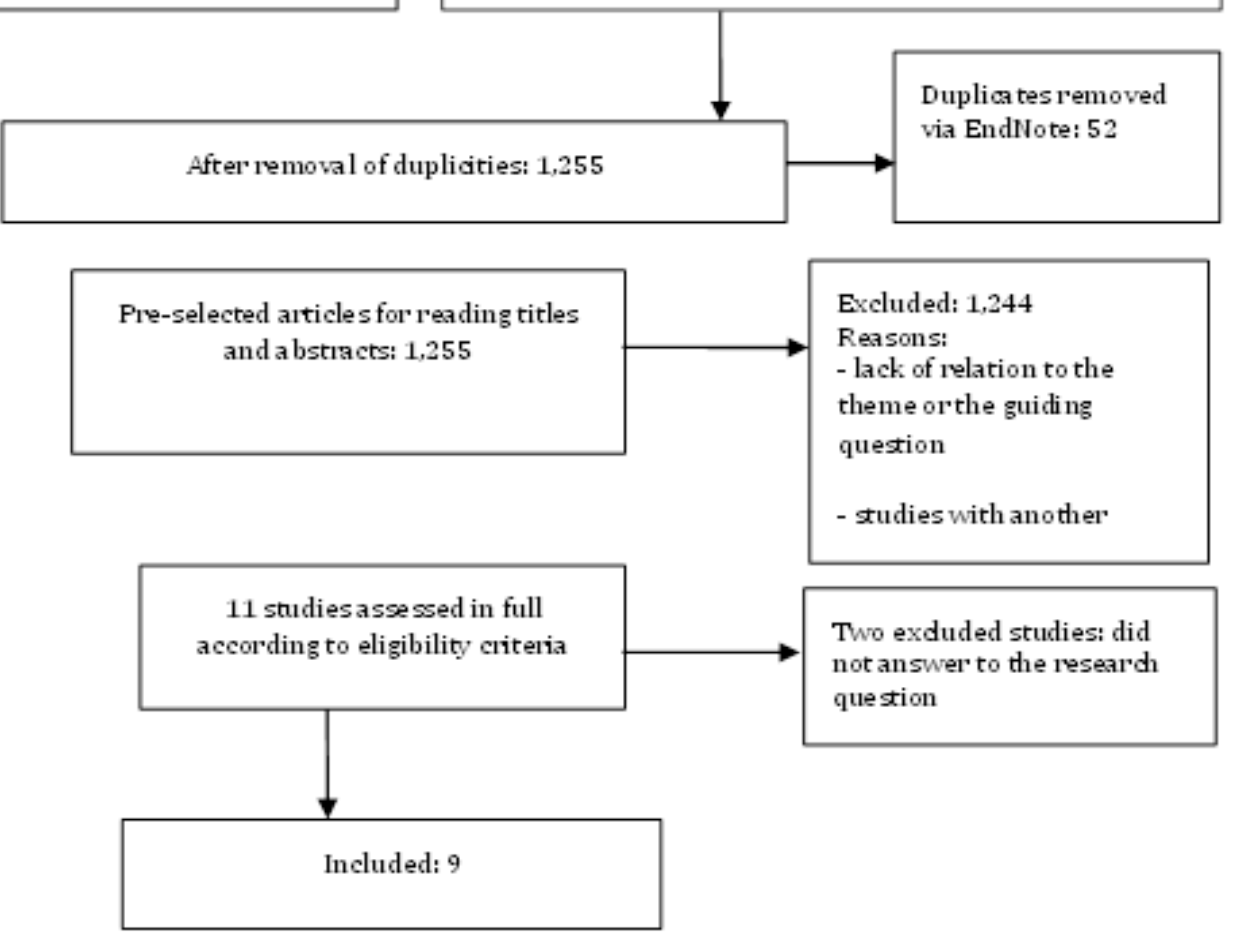

Two exduded studies: did not answer to the researdh question

Figure 1 - Representative scheme of the study selection

\section{Results}

The Joanna Briggs Institute ${ }^{\circledR(5)}$ recommends that the results should clearly describe the studies included in the systematic review. As previously mentioned, a total of nine articles were included in the review, of which eight are quantitative studies and one is a qualitative study. All were published in English, being developed in Iran, South Africa, Australia and
Armenia, which reveals a geographic interest of Asia in this area.

As for the methodological quality of the studies, as can be seen in Table 1, all present a score that exceeds half of the points of each evaluation grid, so that all articles selected after the relevance test II proceeded to the data extraction phase. 
Table 1 - Studies included in relation to the methodological quality score with resource from the Joanna Briggs Institute

\begin{tabular}{|c|c|c|c|}
\hline Authors/year & Study Code & $\begin{array}{l}\text { Level of } \\
\text { Evidence }\end{array}$ & $\begin{array}{c}\text { Score } \\
\text { (points) }\end{array}$ \\
\hline Delpasand et al., $2011^{(8)}$ & A & III-2 & $6 / 8$ \\
\hline Nooryan et al., $2012^{(9)}$ & B & III-2 & $8 / 10$ \\
\hline Nooryan et al., $2013^{(10)}$ & $\mathrm{C}$ & III-2 & $7 / 10$ \\
\hline Towell et al., 2013 & D & IV & $7 / 9$ \\
\hline Sharif et al., $2013^{(12)}$ & $\mathrm{E}$ & II & $8 / 13$ \\
\hline Siffleet et al., $2015^{(13)}$ & $\mathrm{F}$ & IV & $9 / 10$ \\
\hline Tofighi et al., $2015^{(14)}$ & G & III-2 & $6 / 8$ \\
\hline Nagel et al., 2016(15) & $\mathrm{H}$ & IV & $5 / 9$ \\
\hline Saedpanah et al., 2016 ${ }^{(16)}$ & I & III-1 & $9 / 9$ \\
\hline
\end{tabular}

\section{Discussion}

The results of the analyzed evidences have given rise to some conceptual themes related to the factors influencing emotional intelligence (age, sex, emotional experience, training and personality) and their impact (at personal, professional and care levels). All the studies addressed this problem, from different perspectives, some giving more emphasis on the experiences, perceptions and evaluations of emotional intelligence of intensive care nurses, others on the results of intervention programs directed to this population group.

The objective of this research is to identify the factors that influence the emotional intelligence of intensive care nurses. In the studies analyzed, five factors emerged: age, sex, professional experience, training and personality.

Regarding the age, two studies described a tendency for it to correlate positively with emotional capacity, that is, with increasing age, nurses tended to show a greater emotional capacity (study D, study F), while another (study A) revealed that younger nurses were the ones with greater emotional intelligence. Analyzing studies A, D and F, it was verified that none presented significant differences in their results and that study A presented a higher level of scientific evidence, which may support that age is not in itself a factor directly related to emotional intelligence.

On the other hand, in contrast to the quotient of intelligence, which changes little after adolescence, emotional intelligence can be learned and continues to evolve throughout the life cycle as a consequence of the experienced situations ${ }^{(3)}$. Some studies in the literature corroborate these findings, as age is associated with a higher level of emotional intelligence, resulting from maturity and consequently the natural increase of abilities to deal more effectively with pressure and stressful situations ${ }^{(17-20)}$, while other literary studies do not demonstrate this relationship (21-22).

In study $\mathrm{A}$, we found that being male was a variable associated with a higher index of emotional intelligence, with significant differences compared to the female gender $(p=0.048)$. Contrary to these findings, other studies in the literature found that female nurses presented greater emotional intelligence than males, namely in the valorization, expression and regulation of emotions ${ }^{(19,22)}$. Other studies have not identified any association ${ }^{(18,20-21)}$.

Regarding the influence of professional experience on emotional intelligence, nurses felt that previous experiences and knowledge provided them with greater confidence and skills to deal with complex situations, a factor that contributed to their emotional well-being (study F). The nurses from study D who had more professional experience were those who had the higher level of emotional intelligence. However, the results of other studies are contradictory. In study A, nurses with less than 5 years of professional experience were those who had greater emotional intelligence and, as the experience increased, the emotional intelligence decreased. Another article (study $\mathrm{H})$, although without establishing a comparison, also concluded that nurses who are newcomers to intensive care units, and therefore, with little experience, have high levels of emotional intelligence. In all of these studies there were no significant differences. Literature studies also did not identify an association 
between professional experience and emotional intelligence ${ }^{(19,22)}$, while others have demonstrated a relationship with a better capacity to manage different situations $^{(17-18,20-21)}$.

The studies included in this review showed that nurses with post-graduate degree or emotional intelligence training had more emotional intelligence, better civic behavior, and more ability to manage emotions and anxiety compared to nurses without this type of training (studies A, E and F). Training, especially at the level of emotional intelligence, translates into benefits for nurses, even on an individual basis, as their own health status (study E). The literature establishes benefits of post-graduate training ${ }^{(7-18,21)}$ and educational interventions ${ }^{(23)}$ to the level of emotional intelligence of nurses.

The studies $\mathrm{F}$ and $\mathrm{H}$ have shown personality characteristics that relate to the emotional intelligence of intensive care nurses, namely well-being, self-control, emotionality and sociability. Participants who were highly aware of their abilities felt happier, more optimistic, and had more self-esteem, while individuals with lower scores had lower self-esteem and showed disappointment with their lives (study H).

Self-control, characterized by emotional regulation, impulse control and stress management, describes individuals' ability to regulate external pressure, stress, and impulse. Individuals with low levels of self-control tended to be more susceptible to impulsive behaviors, unable to manage stress and were inflexible (study $\mathrm{H}$ ).

High levels of emotionality demonstrated individuals with more ability to perceive and express emotions and use those skills to develop and maintain relationships with others (study $\mathrm{H}$ ). Nurses feeling unable to cope with distress presented cumulative feelings of sadness, suffering, unhappiness, anguish, anxiety, fear, frustration, disappointment, and dissatisfaction. However, individuals who were more able to deal with distress had more behaviors of happiness, pleasure and personal satisfaction (study F).
Sociability was another characteristic identified by the studies, being related to the ability to integrate socially and be assertive with others ${ }^{(24)}$. Individuals with greater sociability tended to believe more in their capacities for active listening and communication (study $\mathrm{H}$ ). The literature establishes a relationship between individuals with positive personality and the tendency of these subjects to value socialization, teamwork and communication ${ }^{(25)}$.

This research was also intended to understand the impact of emotional intelligence on intensive care nurses. The analysis of the articles concluded that emotional intelligence has an impact in three instances: personal, professional and care. The impact at the personal level is mainly related to the emotional exhaustion of nurses and their health status at a global level.

The research developed in study A showed a significant and inverse relationship between emotional intelligence and emotional exhaustion ( $p=0.016$ and $r=-0.234$ ), concluding that the higher the level of emotional intelligence, the less the emotional exhaustion. Data from another study corroborate this evidence, pointing out that nurses who have greater emotional intelligence know themselves better and are able to manage their emotions more adequately, achieving better emotional well-being and, consequently, less emotional exhaustion ${ }^{(26)}$.

The impact of emotional intelligence on a personal level was also presented in study E, which demonstrated that the overall health status of nurses in the intervention group improved after a month of training in emotional intelligence. The literature does not make direct correlations between the general health status of nurses working in intensive care and training in emotional intelligence, however, by the different beneficial correlations that other studies establish between emotional intelligence and anxiety, stress, well-being ${ }^{(9-10,26-27)}$, we can conclude that there is a beneficial impact of emotional intelligence on the overall health status of intensive care nurses.

At a professional level, the impact of emotional 
intelligence is positive and translates into the control of occupational stress and anxiety in the workplace, as well as job satisfaction and bonding to the workplace.

The research data from study I demonstrated that the training of emotional regulation was effective in reducing the occupational stress of intensive care nurses. This is because after the implementation of a training program and development of emotional intelligence in the intervention group, the stress component of these individuals reduced significantly $(\mathrm{p}=0.001)$, while in the control group it remained similar, without significant differences. The dimensions of occupational stress, such as conflict with physicians, problems with peers, workload, uncertainty regarding the treatment and problems related to patients and relatives were significantly different in the intervention group $(\mathrm{p}<0.05)$, in contrast to the control group, in which there were no significant differences. The literature evidence supports the previously exposed results ${ }^{(27)}$, adding that emotional intelligence is related to stress at work and specifically influences the understanding of one's own emotional state and personal fulfillment.

Study C showed that nurses working in intensive care had high levels of (situational and personality) anxiety at work, being reduced after training in emotional intelligence (study $\mathrm{C}$ ). The results of study B showed that the training of emotional intelligence components was effective in reducing the anxiety of participants in the intervention group, and that there is a direct association between increased emotional intelligence and reduction of anxiety. Literature warns of the need to continue to improve training in emotional intelligence to extract constructive and appropriate behavior from nurses in their work, preserving trust, effectiveness and collaboration in the team, thus reducing their anxiety in professional performance ${ }^{(28)}$.

Study A showed a significant correlation between emotional intelligence and job satisfaction ( $p<0.001$ and $r=0.0441$ ), evidencing that improving emotional intelligence can lead to increased job satis- faction. These data are corroborated by the literature, as it demonstrates the influence of emotional intelligence on nurses' well-being and on their productivity. In fact, nurses with high levels of emotional intelligence reported lower levels of emotional exhaustion and psychosomatic symptoms, better emotional health, better teamwork, and greater satisfaction with managers and their work in general. Researchers further add that nurses' training has contributed to self-awareness, self-management, social awareness, and relationship management that shape the personal and social competencies of the nursing profession and increase nurses' emotional intelligence ${ }^{(26)}$. Thus, we can state that, for an effective and successful nursing, the nurse must be able to perceive, understand, regulate and enjoy their emotions. In this sense, job satisfaction seems, in a way, to be a consequence emotional intelligence. A nurse who has an appreciable degree of emotional intelligence in the performance of their work is likely to have higher levels of job satisfaction.

Another impact of emotional intelligence at the professional level is the bonding to work, which is entirely related to the previous theme, since professionals who are more satisfied at the professional level are less likely to leave the profession. Intensive care units cause high levels of stress, anguish and anxiety, which can lead nurses to experience feelings of sadness, suffering, unhappiness, frustration, disappointment and dissatisfaction, which can lead them to abandon the profession (study F). However, when nurses experience feelings of happiness and personal satisfaction, they feel motivated to continue working in intensive care units (study F). Study G reinforces the idea that participants who have high levels of emotional intelligence also have a high degree of bonding to work, with a statistically significant positive correlation $(\mathrm{p}<0.001)$. Evidence from the literature corroborates the data presented above, concluding that emotional intelligence can help nurses to keep involved in their clinical practices and improve nurses' stay and the care provided to clients ${ }^{(29) .}$ 
The impact of emotional intelligence at care level was transversal to all studies. Both in the included studies and in the literature, there is no direct relationship between nursing care and the emotional intelligence of intensive care nurses. This may be due to the complexity of measuring the impact of emotional intelligence on the quality of nursing care, and because this is also a recent topic in the nursing subject. However, the studies included in this review sought to establish relationships between emotional intelligence and different parameters, allowing a better understanding of how to maximize emotional intelligence in order to achieve better quality nursing care.

This systematic review showed that emotional intelligence influences the nurse on a personal, professional and care levels. Scientific evidence is explicit about the influence of training and personality on the emotional intelligence of intensive care nurses. The relationship between age, sex, and work experience with emotional intelligence is still questionable, both from the results of this review and from the literature. The number of studies and their characteristics (objectives, sample, methodological quality, and limitations) do not allow a significant conclusion about how these three factors influence emotional intelligence. Further research is needed in this area.

The analysis of the original empirical studies showed different research designs and methodologies with consequent effect on the results, making it impossible to carry out meta-analysis.

\section{Conclusion}

Emotional intelligence influences the way nurses develop their activity in intensive care units. This is affected by the individual characteristics (age, gender, professional experience, training and personality) and influences the nurse on a personal, professional and care levels. Emotional intelligence must be stimulated in formative contexts.

\section{Collaborations}

Encarnação RMC and Soares EMC contributed to the design, analysis, interpretation of data, article writing and critical review of content. Carvalho ALRF contributed to the design and final approval of the version to be published.

\section{References}

1. Shorter M, Stayt LC. Critical care nurses' experiences of grief in an adult intensive care unit. J Adv Nurs. 2010; 66(1):159-67. doi: https://doi. org/10.1111/j.1365-2648.2009.05191.x

2. Souza VS, Silva DS, Lima LV, Teston EF, Benedetti GMS, Costa MAR, et al. Qualidade de vida dos profissionais de enfermagem atuantes em setores críticos. Rev Cuid. 2009; 9(2):2177-86. doi: https://doi.org/10.15649/cuidarte.v9i2.506

3. Goleman D. Trabalhar com a inteligência emocional. Lisboa: Temas e debates - círculo Leitores; 2014.

4. Rosenstein AH, Stark D. Emotional Intelligence: a critical tool to understand and improve behavior that impact patient care. J Psychol Clin Psychiatry. 2015; 2(1):1-4. doi: https://doi.org/10.15406/ jpcpy.2015.02.00066

5. Joanna Briggs Institute. The Joanna Briggs Institute Reviewers' Manual 2014 - methodology for JBI mixed methods systematic reviews. Australia: The Joanna Briggs Institute; 2014.

6. Higgins J, Green S. Cochrane handbook for systematic reviews of interventions. Inglaterra: John Wiley \& Sons; 2011.

7. Melnyk BM, Fineout-Overholt E, Stetler C, Allan J. Outcomes and implementation strategies from the first U.S. evidence-based practice leadership summit. Worldviews Evid Based Nurs. 2005; 2(3):113-21. doi: https://doi.org/10.1111/ j.1741-6787.2005.00022.x 
8. Delpasand M, Nasiripoor AA, Raiisi P, Shahabi M. The relationship between emotional intelligence and occupational burnout among nurses in critical care units. Iranian J Crit Care Nurs [Internet]. 2011 [cited 2018 July 13]; 4(2):79-86. Available from: https://pdfs.semanticscholar.org/ ddc9/952679499b60fa2c2fe68b2fe12cff0e9aa6. pdf

9. Nooryan K, Gasparyan K, Sharif F, Zoladl M. Controlling anxiety in physicians and nurses working in intensive care units using emotional intelligence items as an anxiety management tool in Iran. Int J Coll Res Int Med Public Health. 2012; 5:5-10. doi: dx.doi.org/10.2147/IJGM.S25850

10. Nooryan K, Gasparyan K, Sharif F, Zoladl M. The effect of Teaching Emotional Intelligence (EI) Items on Job Related Stress in Physicians and Nurses Working in ICU Wards in Hospitals, Yerevan, Armenia. Int J Coll Res Int Med Public Health. 2013; 3(10):703-13. doi: http://dx.doi. org/10.2147/IJGM.S25850

11. Towell A, Nel WE, Muller A. The emotional intelligence of a group of critical-care nurses in South Africa. Health SA Gesondheid. 2013; 18(1). doi: http://dx.doi.org/10.4102/hsag.v18i1.674

12. Sharif F, Rezaie S, Keshavarzi S, Mansoori P, Ghadakpoor S. Teaching emotional intelligence to intensive care unit nurses and their general health: a randomized clinical trial. Int J Occup Environl Med [Internet]. 2013 [cited 2018 July 13]; 4(3):141-8. Available from: http://www. theijoem.com/ijoem/index.php/ijoem/article/ view/208/380

13. Siffleet J, Williams AM, Rapley $P$, Slatyer S. Delivering best care and maintaining emotional wellbeing in the intensive care unit: the perspective of experienced nurses. Appl Nurs Res. 2015; 28(4):305-10. doi: http://dx.doi. org/10.1016/j.apnr.2015.02.008

14. Tofighi M, Tirgari B, Fooladvandi M, Rasouli F, Jalali M. Relationship between emotional intelligence and organizational citizenship behavior in critical and emergency nurses in south east of Iran. Ethiop J Health Sci. 2015; 25(1):79-88. doi: http://dx.doi. org/10.4314/ejhs.v25i1.11
15. Nagel Y, Towell A, Nel E, Foxall F. The emotional intelligence of registered nurses commencing critical care nursing. Curationis. 2016; 39(1):e1-7. doi: dx.doi.org/10.4102/curationis.v39i1.1606

16. Saedpanah D, Salehi S, Moghaddam LF. The effect of emotion regulation training on occupational stress of critical care nurses. J Clin Diagn Res. 2016; 10(12):1-4. doi: http://dx.doi.org/10.7860/ JCDR/2016/23693.9042

17. Papageorgiou D, Mpolioudaki E, Papala E, Prifti $\mathrm{S}$, Kagialari M. Investigation of factors that influence the development of emotional intelligence in nurses. Nosileftiki [Internet]. 2011 [cited 2018 July 13];50(2):185-93. Available from: www.researchgate.net/publication/292836860_Investigation_of_factors_that_influence_the_development_of_emotional_intelligence_in_nurses

18. Alves J, Ribeiro C, Campos S. A inteligência emocional em enfermeiros responsáveis por serviços hospitalares. Rev Enf Ref. 2012; serIII(7):33-42. doi: http://dx.doi.org/10.12707/ RIII1199

19. Snowden A, Stenhouse R, Young J, Carver H, Carver F, Brown N. The relationship between emotional intelligence, previous caring experience and mindfulness in student nurses and midwives: a cross sectional analysis. Nurse Educ Today. 2015; 35(1):152-8. doi: http://dx.doi.org/10.1016/j. nedt.2014.09.004

20. Srinivasan K, Samuel U. A study on emotional intelligence of staff nurses working in Villupuram district. J Hum Soc Sci. 2016; 21(3):34-9. doi: http://dx.doi.org/10.9790/0837-2103043439

21. Kahraman N, Hiçdurmaz D. Identifying emotional intelligence skills of Turkish clinical nurses according to sociodemographic and professional variables. J Clin Nurs. 2016; 25(7-8):1006-15. doi: http://dx.doi.org/10.1111/jocn.13122

22. Arrogante0,ZaldívarE.Factoressociodemográficos relacionados con la inteligencia emocional en los profesionales de Enfermería. Metas Enferm [Internet]. 2016 [citado 2018 jun. 20]; 19(6):6873. Disponível em: https://dialnet.unirioja.es/ servlet/articulo?codigo $=5566558$ 
23. Zijlmans LJ, Embregts PJ, Gerits L, Bosman AM, Derksen JJ. The effectiveness of staff training focused on increasing emotional intelligence and improving interaction between support staff and clients. J Intellect Disabil Res. 2015; 59(7):599612. doi: http://dx.doi.org/10.1111/jir.12164

24. Bar-On R. Emotional and social intelligence: Insights from the emotional quotient inventory. In: Bar-On R, Parker JDA. The Handbook of emotional intelligence. San Francisco: Jossey-Bass; 2000. p.363-88.

25. Edbor A, Singh P. The role of emotional intelligence on personality. Indian J Positive Psychol [Internet]. 2016 [cited 2018 July 26]; 7(1). Disponível em: https://www.questia.com/ library/journal/1P3-4055684071/the-role-ofemotional-intelligence-on-personality
26. Tagoe T, Quarshie EN. The relationship between emotional intelligence and job satisfaction among nurses in Accra. Nurs Open. 2017; 4(2):84-9. doi: http://dx.doi.org/10.1002/nop2.70

27. Nespereira-Campuzano T, Vázquez-Campo $M$. Emotional intelligence and stress management in nursing professionals in a hospital emergency department. Enferm Clin. 2017; 27(3):172-8. doi: http://dx.doi.org/10.1016/j.enfcli.2017.02.007

28. Jones TL, Argentino D. Nurse-to-nurse hostility, confrontational anxiety, and emotional intelligence: an integral, descriptive pilot study. J Perianesth Nurs. 2010; 25(4):233-41. doi: http://dx. doi.org/10.1016/j.jopan.2010.05.010

29. Kokker BM, Shoultz J, Codier E. Identifying emotional intelligence in professional nursing practice. J Prof Nurs. 2007; 23(1):30-6. doi: http:// dx.doi.org/10.1016/j.profnurs. 2006.12.004 